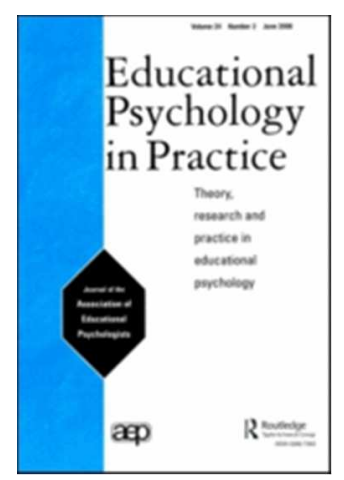

\title{
Lesson study: an inter-professional collaboration approach for Educational Psychologists to improve teaching and learning.
}

\begin{tabular}{|r|l|}
\hline Journal: & Educational Psychology in Practice \\
\hline Manuscript ID & CEPP-2017-0053.R2 \\
\hline Manuscript Type: & Research \\
\hline Keywords: & $\begin{array}{l}\text { lesson study, working memory, inter-professional collaboration, learning } \\
\text { difficulties, distance technology }\end{array}$ \\
\hline \multicolumn{2}{|l}{} \\
\hline
\end{tabular}

\section{SCHOLARONE}

Manuscripts 


\begin{tabular}{|c|c|}
\hline \multicolumn{2}{|c|}{ Secondary school team members: 2 maths teachers, SENCo and EP } \\
\hline $\begin{array}{l}\text { Lesson study 1: Case } \\
\text { pupils }\end{array}$ & $\begin{array}{l}\text { Year } 10 \text { male and female pupils. Male had difficulties retaining maths } \\
\text { concepts / procedures (autism diagnosis). Female poor self-concept, } \\
\text { fear of failure. In class of lower math attainment ( } 3 \text { pupils with } \\
\text { Education, Health and Care (EHC) Plans) }\end{array}$ \\
\hline $\begin{array}{l}\text { LS1: Research lesson } \\
\text { focus }\end{array}$ & $\begin{array}{l}\text { Adding and subtracting single digit numbers; pupil 1: confident to } \\
\text { solve problems without support; pupil 2: to raise maths self-esteem } \\
\text { and work independently. Use visual concrete methods (blue } \\
\text { counters for positive and red for negative numbers) in the context of } \\
\text { group work. Concrete rewards for correct answers. }\end{array}$ \\
\hline $\begin{array}{l}\text { Team interaction and } \\
\text { technical issues }\end{array}$ & $\begin{array}{l}\text { Positive team interactions and insightful evaluation of case pupils' } \\
\text { learning. Skype link to EP worked well, but iPad photos and short } \\
\text { clips used instead of videos. }\end{array}$ \\
\hline What learned from LS1 & $\begin{array}{l}\text { Positive confidence and increased understanding as pupil outcomes. } \\
\text { Resource usable in other lessons within topic. Remove concrete } \\
\text { resources slowly to embed understanding of the task. Some } \\
\text { negative attitude to resources, but case pupils kept using them. For } \\
\text { teachers enabled confidence to be creative in teaching. Blame free } \\
\text { setting supports risk-taking. }\end{array}$ \\
\hline & 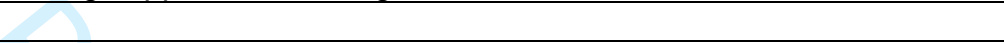 \\
\hline $\begin{array}{l}\text { Lesson study 2: Case } \\
\text { pupils }\end{array}$ & $\begin{array}{l}\text { Year } 7 \text { male and female pupils. Pupil } 1 \text { low self-esteem, struggles to } \\
\text { work independently; pupil } 2 \text { distracted from and disinterested in } \\
\text { learning, but responds to praise. }\end{array}$ \\
\hline $\begin{array}{l}\text { LS2: Research lesson } \\
\text { focus }\end{array}$ & $\begin{array}{l}\text { Focus on pupils engaging more than } 2 \text { minutes of adding / } \\
\text { subtracting fractions with different denominators and to explain how } \\
\text { to add fractions. Built on LS } 1 \text {; used concrete scaffolds. Identified } \\
\text { one pupil as having insecure reactive attachment based on observed } \\
\text { hypervigilant behaviour. Tried clearer and secure boundaries. } \\
\text { Fractions represented as drawn boxes in which mini-eggs were } \\
\text { placed. }\end{array}$ \\
\hline $\begin{array}{l}\text { Team interaction and } \\
\text { technical issues }\end{array}$ & As in LS1 \\
\hline What learned from LS2 & $\begin{array}{l}\text { Positive impact on progress with fractions, attributed to practical } \\
\text { methods and self-discovery leading to embedded learning. } \\
\text { More insight about how one pupil learned: the more she contributed } \\
\text { the less she understood, perhaps acting as a coping mechanism. } \\
\text { More time needed than has previously been allocated to embed their } \\
\text { learning. EP contributed to deeper understanding of the behaviour } \\
\text { that helped improve learning. }\end{array}$ \\
\hline
\end{tabular}

Table 1: Summary of secondary school LS cycles

\begin{tabular}{|c|c|c|c|}
\hline $\begin{array}{l}\text { Total score range: } 0-32: \\
\text { Mean scale score range: } 0-4\end{array}$ & Secondary school $(n=4)$ & $\begin{array}{l}\text { Primary school } \\
(n=3)\end{array}$ & Special school $(n=3)$ \\
\hline $\begin{array}{l}\text { Mean total score } \\
\text { Mean scale score }\end{array}$ & $\begin{array}{c}24.3 \\
3.0\end{array}$ & $\begin{array}{c}24.0 \\
3.0\end{array}$ & $\begin{array}{c}27.7 \\
3.5\end{array}$ \\
\hline Overall: 2 highest items & \multicolumn{3}{|c|}{$\begin{array}{l}\text { Team followed LS steps }(3.4 / 4) \& \\
\text { Meetings long enough }(3.3 / 4)\end{array}$} \\
\hline Overall: lowest items & Case pupils interviewed at & nd of research les & $9 / 4)$ \\
\hline
\end{tabular}

Table 2: Ratings of Lesson study implementation fidelity 


\begin{tabular}{|l|l|l|l|}
\hline $\begin{array}{l}\text { PROCESS } \\
\text { (scale range }-14 \text { to }+14: \\
-2 \text { to }+2 \times 7 \text { items) }\end{array}$ & Secondary school $(n=4)$ & Primary school $(n=3)$ & Special school $(n=3)$ \\
\hline Mean /max score & $11 / 14$ & $10.3 / 14$ & $11.3 / 14$ \\
\hline Lowest process factor & \multicolumn{3}{|c|}{ Working memory ideas used constructively } \\
\hline Highest process factor & \multicolumn{2}{|c|}{ Constructive / supportive team relationships } \\
\cline { 2 - 4 } & LS engaged team in meetings $\begin{array}{l}\text { Contributions of LS members } \\
\text { equal value }\end{array}$ \\
\hline
\end{tabular}

Table 3: LS process scores

\begin{tabular}{|c|c|c|c|}
\hline $\begin{array}{l}\text { CONTEXT } \\
\text { (scale range: }-14 \text { to } 14 \text { ) }\end{array}$ & Secondary school $(n=4)$ & Primary school $(n=3)$ & Special school $(n=3)$ \\
\hline Mean & 4.5 & 3.7 & 11.7 \\
\hline \multirow{2}{*}{$\begin{array}{l}\text { Most negative / low context } \\
\text { factor }\end{array}$} & \multicolumn{2}{|c|}{ Timetable inflexibility } & \multirow[t]{2}{*}{ None } \\
\hline & School little experi & f teacher-centred CPD & \\
\hline \multirow[t]{2}{*}{ Most positive context factor } & \multicolumn{3}{|c|}{ Participants committed to LS } \\
\hline & \multicolumn{3}{|c|}{ Participants prepared and supported for trial } \\
\hline
\end{tabular}

Table 4: LS context scores 


\section{STUDY}

\section{REVIEW}

\section{PLAN}

TEACH

Figure 2: Lesson planning sequence in Lesson Study and professional knowledge

Educational Psychologist joins team in RP meeting 1, 3 \& 4 by video-link and attends RP meeting 2 after observing in RL1 \& watches videos / pictures of RL2 \& 3

Figure 1: Inter-professional Lesson Study model

\section{TACH}


$\mathrm{RL}=$ research lesson; $\mathrm{RP}=$ review and planning meeting

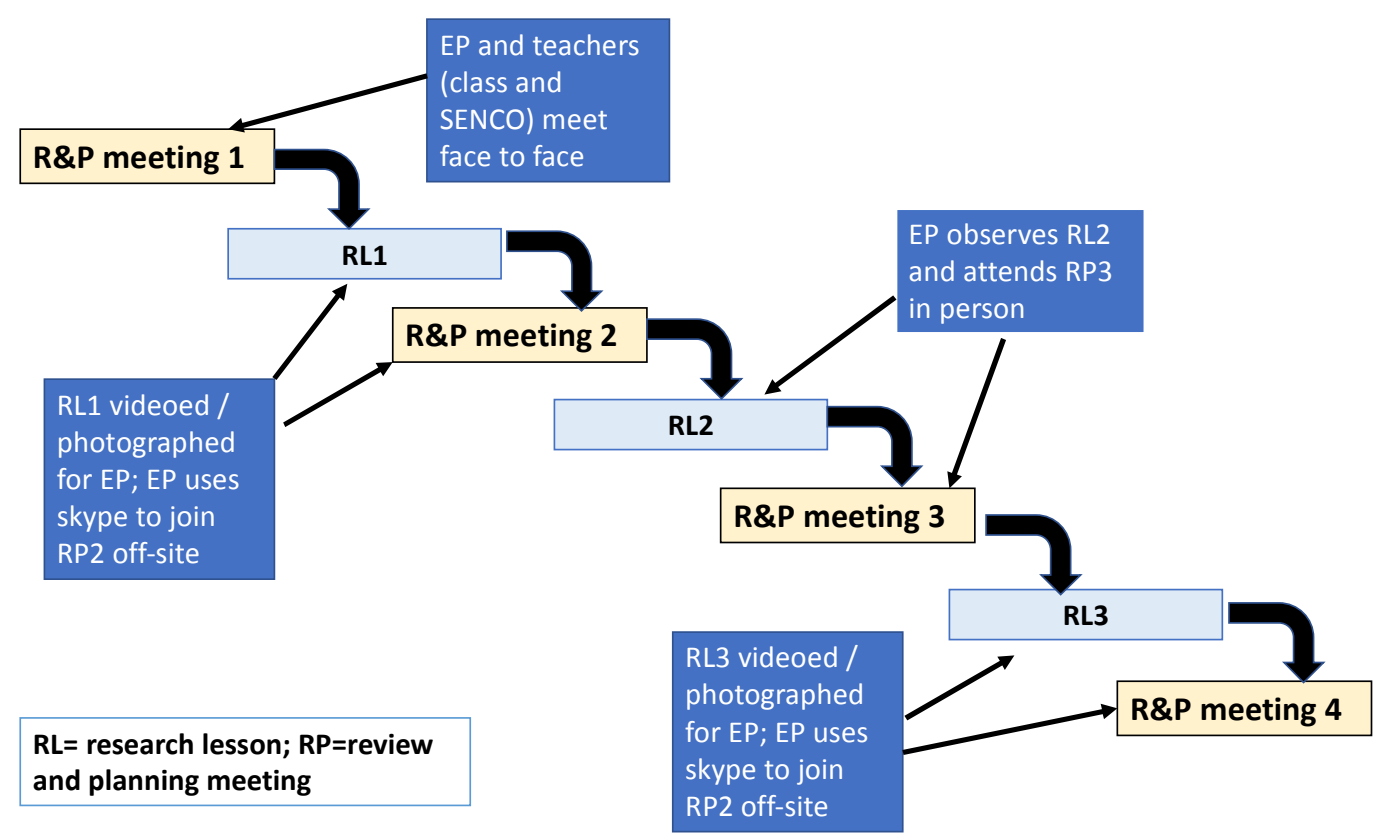

Figure 3: How EPs communicated with teachers in LS process

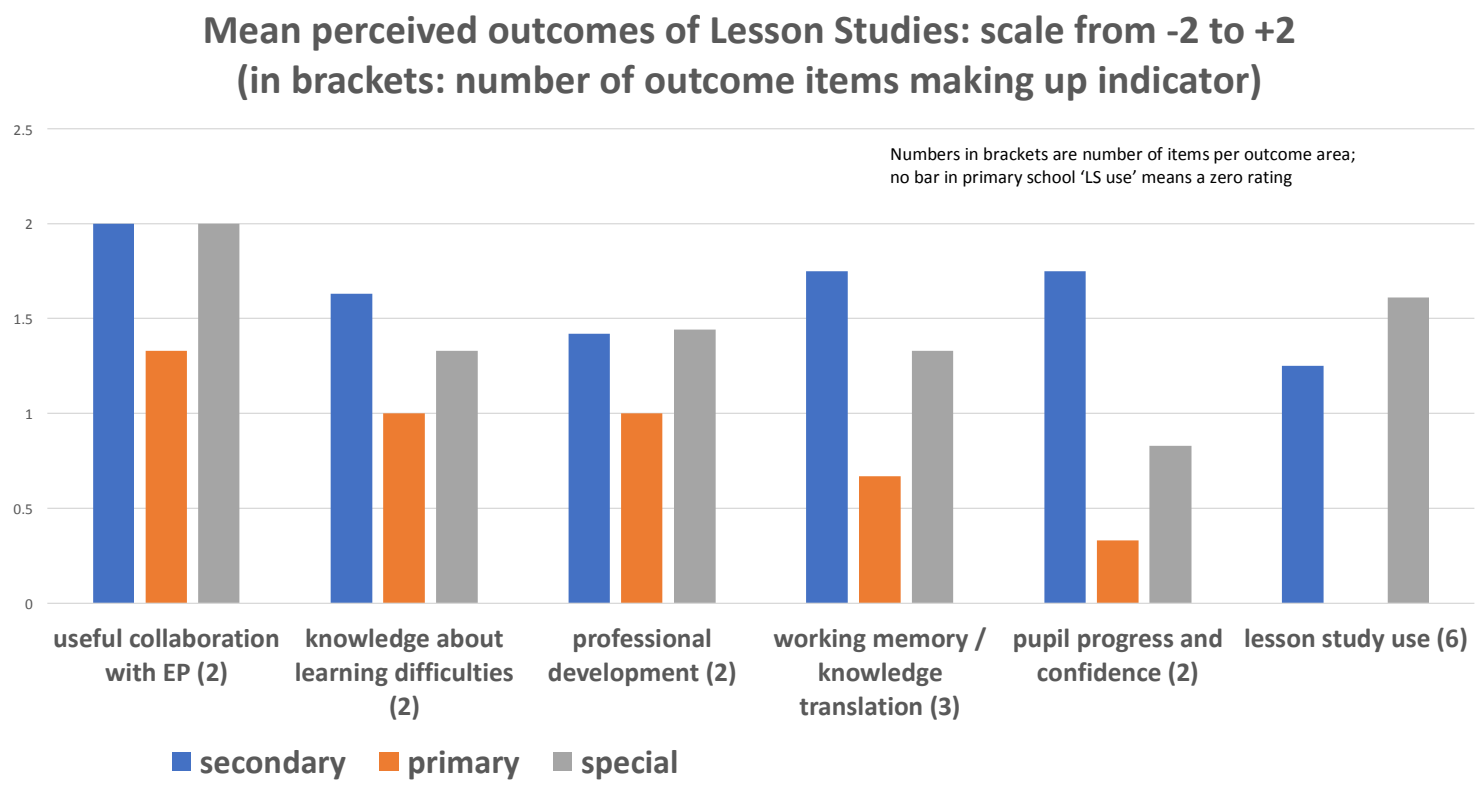

Figure 4: Perceived LS outcome organised into 6 areas 


\section{Lesson study: an inter-professional collaboration approach for Educational \\ Psychologists to improve teaching and learning.}

Brahm Norwich*, Taro Fujita*, Anna Adlam+, Fraser Milton+ and Andrew Edwards-Jones ^. ${ }^{*}$ Graduate School of Education, +Department of Psychology, University of Exeter

$\wedge$ University of Plymouth

\section{Corresponding author, Brahm Norwich, B.Norwich@exeter.ac.uk}

This paper describes an innovative use of lesson study (LS), an internationally used collaborative approach in which teachers develop their teaching knowledge and practices. It aimed to evaluate how EPs join teachers in LS teams, using working memory and other knowledge to inform the teaching of pupils with learning difficulties. The study uses a case study methodology to evaluate LS teams (3 teachers and EP) in a primary, secondary and special school. The findings show how working memory knowledge is used in reviewing and planning research lessons, how the teams interact, including the teachers' perceived EP contribution to the lesson study process. The paper illustrates the potential of an interprofessional LS study to embody collaborative reflective practice in order to improve the teaching of pupils with learning difficulties.

Key words: lesson study, inter-professional collaboration, working memory, learning difficulties

\section{Introduction}

The work of practitioner educational psychologists (EPs) has been described in terms of: whether. the focus is on individual children or the system in which they live and learn; and whether it is direct work with the child or indirect, with a system, working through others. Consulting with a group of SEN Coordinators (SENCOs) could be seen as indirect systems work, while counselling an individual child as direct individual work. The focus of this paper is 
an inter-professional version of Lesson Study, which cannot be easily described in terms of these two distinctions. The EPs' work in Lesson Study (LS) (Lewis, 1998) can be seen to have elements which cut across these distinctions, as it will emerge in what follows.

Lesson Study, which was originally developed in Japan over a century ago, is a collaborative form of professional development involving an elaborated version of a plan-do-review model of practice (Lewis, 1998). It has come to prominence over the last 20 years internationally in different variations including the UK, other European countries and the USA, though its centre of activity is still in the Far East (Japan, Singapore, Hong Kong, China) reference required.

Despite some variations in LS practice, the basic principle involves small group teacher collaboration to develop a series of research lessons in which different approaches to teaching are tried to improve specific forms of pupil learning, with the aim of enhancing teaching knowledge (Takahashi and Yoshida, 2004). In the UK version of LS (Dudley, 2012), the LS cycle usually consists of three research lessons (RLs), each preceded and followed by review and planning meetings (RP). LS teams consist of teachers who focus on case pupils in the planning, teaching and evaluation of the research lessons. These pupils are identified depending on the topic and aims of the LS (Dudley, 2012). The team is involved in jointly planning the research lessons and while one of the team teaches the lessons, the others observe the case pupils' learning. Figure 1 shows the inter-professional lesson study model used in this study.

This paper reports on findings from the innovative use of LS as a form of Inter-professional collaboration that includes schools' own EPs. This study is part of a series of research and development trials that have extended LS principles and procedures to be relevant to inclusive teaching, the dynamic assessment of learning needs (Elliott, 2003) and inter-professional collaboration. Most uses of LS have mainly focused on traditional curriculum subjects, 
especially but not exclusively mathematics (see content of International Journal of Lesson and Learning Studies; IJLLS, 2018). Few studies have been in relation to inclusive and special needs education, these include Chia (2013) who used LS for the training of special education teachers in Singapore to include support staff from health services, and Goei, Cai and Kee (2017) who applied LS in inclusive settings in the Netherlands.

Figure 1 here

Lesson Study resembles various problem solving approaches used by EPs to support teachers. Bennett and Monsen (2011) review four of these approaches: Circles of Adults; Teacher Coaching; Collaborative Problem-solving Groups, and the Staff Sharing Scheme. All involve a problem-solving sequence and differ according to their person-centredness, the role of an external coach / facilitator, the number of meetings and who is involved. While Bennett and Monsen recognise in their critical evaluation the potential of these approaches, they also identify the need to develop a more robust evidence base before they can be developed any further. Their review, however, does not cover another similar approach, Teacher Support Teams, developed in the UK and based on a model, which also resembles LS (Creese, Daniels and Norwich, 1997).

Despite the similarities between LS and these collaborative problem-solving approaches, there are some crucial differences. LS is an approach for teachers run by teachers and does not use an external facilitator or coach, though it may involve an external 'expert' within the LS team, as described in this paper (Lewis, Perry, Hurd \& O'Connell, 2006). LS is primarily focused on improving teaching that relates to the academic curriculum and less so on dealing with challenging behaviour, unlike some of the above schemes. However, LS can combine academic and social-behavioural goals. Thirdly, LS involves a lesson planning sequence rather than a problem-solving sequence which adds a study stage to the typical plan-do-review 
sequence (see Figure 2). The study stage is a key element that corresponds to the contribution of a relevant knowledge base to the LS sequence as in Figure 1 above. The study phase is when the LS team examines the learning of the case pupils in the research lesson by drawing on professional knowledge, and knowledge of various curricula and research-informed concepts and approaches to understand what is going on and to develop the plans for the next research lesson (Lewis and Hurd, 2011).

Figure 2 here

This study builds on a programme of three previous trials. The first trial developed adapted teaching of secondary school pupils with moderate learning difficulties, involving subject class teachers and SENCos (Norwich and Ylonen, 2013; Norwich and Jones, 2014). In the second trial LS was used to assess case pupil learning in response to the team planned teaching in the research lessons, what is called Lesson Study for assessment involving class teachers and SENCos (Norwich, Dudley and Ylonen, 2014). In the third trial LS was used to develop adapted teaching approaches with the LS team, including class teachers and university based mathematics educationalists and practitioner or research psychologists (Norwich, Koutsouris, Fujita, Ralph, Adlam \& Milton, 2016).

This paper is about a fourth trial which involved inter-professional collaboration with schools' educational psychologists. The purpose in this trial was to develop adapted teaching approaches in mathematics, informed by working memory theory and practices. Recent working memory research indicates that training working memory capacity has not been 
effective in a consistent way (Apter, 2012), so that researchers recommend that teachers take account of work memory difficulties in their teaching (Gathercole, 2008; Gathercole and Alloway, 2008). Using a knowledge of working memory difficulties and making adaptations for pupils with such difficulties is something that LS can be used for, so was a suitable knowledge base for this trial. The LS team members were class teachers, the school's SENCo (mainstream schools only) and the school's practitioner educational psychologist. There were two key aims of this trial:

1. To use concepts and practice associated with working memory in a LS that involved an EP working with teachers to enhance the teaching of children with learning difficulties.

2. To develop a model of LS which included the school's EP which takes account that the EP could not attend all the review and planning meetings and research lessons in person.

\section{Lesson Study practices and preparation:}

Three English urban schools (one primary, one secondary and one secondary special) participated in this trial. Each had four LS members (two class teachers, one SENCo and one EP). This trial used the UK version of LS (3 research lessons with a focus on 2 case pupils, identified by the team members as having learning difficulties, as in Figure 1). Each team undertook two cycles of LS over two terms, though the duration of a cycle varied (from one week to three weeks). The focus of the second cycle was either on a different set of case pupils in the same or a different class, with a different teacher teaching the research lessons.

The teams were introduced to lesson study principles and practices and to relevant knowledge bases (mathematics and working memory) at a one day professional development conference. The secondary school SENCo had extensive experience of using LS, but the EP and class teachers did not. 
Figure 3 here

Figure 3 shows which research and planning meetings the EP attended in school and which used video link. It also shows which research lessons the EP attended and when case pupils' learning was videoed or photographed to send to the EP. All participants were also provided with a LS guidance booklet which set out the steps in a LS cycle (which followed the sequence as shown in Figure 1). For each step there are also templates to record decisions, assessments and lesson plans in note form. These templates also act as prompts for each step in the process.

To provide each LS team with a functional assessment of their case pupil's working memory, four aspects of the working memory of 11 case pupils were assessed (three schools x two LS cycles $x$ two case pupils; with one pupil not assessed) by the project researcher using the Automated Working Memory Assessment system (AWMA; Alloway, 2007). This covered verbal short term and working memory, visuo-spatial short term and working memory profiles. Teams were given the working memory profiles for each case pupil and summaries of the teaching implications of working memory functioning. Between the first and second LS cycle, the project team made contact with each team and asked if they had any questions or problems that arose.

After the two cycles of LS the teams met with the members of the project team to review the project. Each team presented a summary of their two LS cycles with provided headings. Table 1 below summarises the details of the two secondary school LS cycles (as an example). 
Table 1 here

\section{Evaluation design}

This lesson study trial was evaluated using a case study methodology (Robson and McCarten, 2015) involving quantitative and qualitative data with each school's LS team as the unit of analysis. Given the two trial aims, the following evaluation questions were addressed:

1. To what extent were LS procedures seen to have been implemented by group members?

2. To what extent and how was working memory knowledge translated into teaching practice?

3. How did the LS group interact with each other?

4. What were the perceived contributions of EPs to the LS process?

5. What LS outcomes were identified by team members?

6. What processes were seen to underlie these LS outcomes?

7. What contexts were seen to affect these outcomes?

Data collection and analysis:

The following data were collected:

1. Transcripts were made of the full audio recordings of 19 of the 24 review and planning meetings (lasting 45-60 minutes each) from both LS cycles in each school (recorded by a designated team member and sent to an evaluation research team for transcription). These were analysed thematically for each LS team separately using NVIVO qualitative data analysis software (NVIVO, 2018), and informed by the LS themes from a previous study (Parks, 2008) (see appendix for broad themes used in coding meeting transcripts; contact lead author for more details of thematic analysis). 
2. At the 'end of project' cross school review meeting, all LS teams presented a summary of their LS cycles as power-point slides and an oral account. The oral accounts were recorded, transcribed and analysed with the data from 1 above.

3. At the end of the two LS cycles EPs were interviewed individually and teachers as a group using a semi-structured format. The schedules covered the following topics: aims of trial, knowledge used, LS implementation and communications, LS outcomes, LS processes (mechanisms) and LS context. These were recorded, transcribed and analysed with the above data. The interview schedule and questionnaire design (4: below) were informed by realist evaluation principles, as used in Ylonen and Norwich (2013).

4. 10 of the 12 LS team members completed a LS Context-Mechanism-Outcomes (CMO) questionnaire consisting of a 5 point rating scale against 30 statements about their beliefs of the LS outcomes (15 items), the processes underlying these outcomes (7 items) and contexts ( 7 items) that supported or inhibited the processes and outcomes (based on Norwich \& Ylonen, 2013). The scale ranged from 'very much like this' at the positive end to 'not very much like this' at the negative end.

5. LS implementation questionnaire of 8 items on a 5 point Likert scale ('not at all' to 'very much') that explored the application of procedural elements to the LS practices.

Relevant selections of questionnaire ratings and thematic analyses were used to address each evaluation question.

\section{Ethics:}

Ethics clearance was provided by the Exeter University Ethics Committee to confirm the study followed usual ethical principles.

\section{Findings}


The findings will be presented mainly as cross case comparisons and only partly in terms of individual LS cases because of the word limit for this paper.

\section{LS procedures implemented}

Table 2 shows across the three teams a fairly high level of LS implementation: most mean scale scores are 3.0 or above (maximum was 4.0 ). The highest overall statement rating was about following the LS steps and the meetings lasting long enough, while the lowest rated statement was about interviewing case pupils at the end of research lessons, but even here this was only just below the 3.0 level. As Tables 3 above indicated, the secondary team saw the video meetings as working well but they used short tablet video clips taken rather than longer videos. In the primary school, however, the team reported some staff absence from meetings and research lessons which they saw as affecting the completeness of the LS process.

Table 2 here

\section{Working memory knowledge translated}

Table 3 below shows that across the three schools the statement about the constructive use of working memory ideas (CMO questionnaire) had the lowest process score, though it was still rated positively.

All EPs in the first review and planning meeting discussed with their teams the significance of the working memory profiles for the case pupils. In the secondary school, for example, the SENCo who knew two of the case pupils believed that the profiles were a 'fair reflection of the pupils'. By contrast, in the special school team there was a teacher who doubted the validity of the working memory concept and its use. This arose from this teacher having studied a humanist psychology course which was critical of cognitive psychology and working memory 
theories. The EP sidestepped this and suggested that they consider teaching accommodations, referring to research showing that working memory difficulties are hard to remediate:

'Just do accommodations... basically the bottom line is - supporting working memory is going to be really important.'

That other teachers in this team were receptive to working memory ideas was shown by discussion during the first meeting about what they read about the implications of working memory ideas for teaching approaches.

Changes in research lesson teaching which were informed by a working memory perspective were evident in the special school team, as shown by several sources of evidence. The main change involved adding a step before the pupils started a task; the team decided to provide a paper version of what was to be copied from the white board rather than having case pupils copy from the white board onto paper before they started the task. By providing a paper version of what was to be copied they removed a step which aided the case pupils. The team also saw it as something which other pupils could use as an option. However, this team did still wonder whether removing this step in the task was about supporting working memory or reducing distractions, but concluded that:

'we all agreed that there was partly a working memory factor but we didn't know to what degree'.

Even the teacher who initially doubted the working memory ideas agreed with this, not connecting this later view with his earlier views. During one of the team meetings this teacher began to consider how a limited capacity working memory would affect what pupils could do in various learning tasks. He then said:

'I would never have thought that I would have this conversation (laughs) 'cos I'm not a cognitive psychologist, I'm a humanist psychologist'. 
When summarising the primary school LS cycles, one teacher reported how they used the working memory profile to discuss how to reduce the:

'cognitive load so that pupils would not be over-burdened with a load of information'.

\begin{abstract}
Analysis of the meeting transcripts also showed how the EP explained the difference between short term memory and working memory. In another meeting the EP suggested that teaching in the research lesson involved too many verbal questions and 'potentially overloading' the case pupils, with the implication that fewer questions needed to be asked. This EP also suggested thinking in terms of how stress might divert cognitive resources from working memory. For this EP, working memory ideas were part of his 'pool of knowledge' that he uses with teachers and SENCos typically when consulting with them. Both the teachers and this EP, when summarising the LS cycles, asserted that working memory ideas had some use in LS meetings, but agreed with the teachers that the effectiveness of LS was mainly about: 'professionals around the table, not the theoretical or mathematical base of the knowledge exchange'.
\end{abstract}

The EP in the secondary school LS team believed that the teachers had some knowledge about:

'the memory system as multi-layered and that there is a part of it which holds information on a short-term basis'.

Analysis of the meeting discussions showed that the team designed the research lessons by combining knowledge about concrete/visual maths representations with working memory ideas. For example, the EP explained at one stage that what they were aiming to do was to give the case pupils:

'a concrete concept that once they'd practised it, moves onto paper and then moves into their head'. 
She saw this as: 'an externalisation of short term memory'. It is relevant that this EP reported that she had only used working memory ideas at a basic level in her prior practice.

All the EPs described how they also used other areas of knowledge in the LS review and planning meetings. These covered, self-efficacy, self-concepts, about long-term memory not just working memory, attachment theory in relation to pupils' distrust of adults and communication and social dynamics between pupils.

\section{LS group interactions}

The teams coordinated their interactions in different ways. In the special school there was no formal chairperson, but the EP assumed this role informally by using the templates to prompt the next steps in the process. In the secondary school, it was agreed that the EP chair the meetings while the SENCo recorded using the templates. By contrast there was no chair in the primary school team with different members moving the process forward at different stages.

All three teams reported and showed from the review and planning meeting transcripts that they collaborated well in an effective and positive way. For the secondary EP the LS team exemplified positive inter-professional collaboration between all members. Having a sense of trust between the team members was also referred to as very important. This involved feeling safe in the team, for example, as one primary teacher put it: 'not feeling that you were being judged'.

Across each of the teams there were many examples of members asking questions of each other for various reasons. There were examples of EPs asking questions to progress the process (informally coordinating the interactions), of all members asking about what happened 
in case pupils' learning as well as why it happened. Other questions were about lesson planning and some were suggestive of possible interpretations.

There were also several examples across all three teams of members responding to others' points and building on others' views and advice. Some of the interactions were also about reinforcing others' ideas and suggestions, with phrases like 'that's really good thinking'. Analysis of the transcripts also showed examples of team members being open to advice from others, someone modelling how to teach as part of a research lesson, and challenging others' views. In the special school team, the teacher described how nobody's views took priority over others' views.

\section{EP contribution to $L S$}

The EP in the special school team saw her contribution as engaging a team of teachers to: 'ask curious questions, try to help other people to explore what might have been going on and how might we be testing this and challenge that or see if we can make a difference'.

For her this was using her consultation skills. While one of the teachers saw the EP role as 'reaffirming' what they knew about pupils, the other two teachers saw the EP as making practical suggestions that were helpful, 'even if they were ones that teachers knew and had tried before'. The other teacher remarked:

'I don't think we would have necessarily picked it up ... it was as a result of the EP's input and from our own observations'.

The EP was also seen as enhancing the LS process and seen by some as like 'a fourth teacher'.

While the secondary school EP had some initial doubts about her contribution given the SENCo's considerable knowledge of learning needs, and the class teachers' maths teaching 
skills, she believed that she had listened to the teachers so they discussed matters with her. This allayed her fears of being put into an expert role. The LS process had been a 'learning experience' for the EP as she felt it was rare for EPs to work with secondary school teachers. The SENCO believed that the EP's contribution really helped them:

'to think at much more depth than we previously would have'.

This was about reconsidering the:

'barriers that the students had and the ways to get round those'.

For the primary school EP, the LS process had been a 'very intensive piece of work' given that he would normally not be used for children like the case pupils, as they might not be a school priority for the EP's involvement. For him the LS process was a very interesting way of:

'bringing psychology to bear on improving teaching practices'.

For one LS teacher, this EP brought a 'really useful perspective' on how children think and feel that contrasted with teachers, who focused on 'resources that worked well'. For another this EP looked from a 'theoretical point of view' while still being:

'interested in the practical and the delivery side of things'.

As an example, one teacher explained how this EP noticed how a case pupil:

'was considerably more able than she had shown, that she couldn't handle the anxiety of being put on the spot and being asked a question'.

Based on this observation it was decided to give the case pupil more time to process, leading her to improve the number of correct responses she gave.

\section{Team identified outcomes}

The $15 \mathrm{CMO}$ questionnaire statements about LS outcomes were organized into six broad areas as illustrated in Figure 4, which shows the overall positive outcome ratings across the three schools. This shows the ratings for the primary school team were lower than the other two schools, with ratings for three of the outcome areas below +1 and one of three areas at 
zero. But, none of the means were negative, though some primary school LS members gave negative ratings about the future use of LS.

The pattern of ratings across and within the schools in Figure 4 was broadly consistent with the interview and meeting transcript analyses.

\section{Figure 4 here}

Interviews showed that teachers across the schools saw LS as providing the opportunity for indepth analysis of individual pupils' learning, what a teacher in the special school called:

'reflective practice, something which they rarely experienced'.

For another special school teacher, this was about being:

'able to slow down talk amongst ourselves'.

Others in that team recognised 'a bit of extra work for everybody', but believed that it could be fitted into their routine. Teachers across at least two of the three teams identified the following positive outcomes from the LS: value of observing their own pupils taught by another teacher, improved understanding of learners, confidence to try something different, developing a clearer understanding about learning process, changes in teaching practice and better understanding of the teaching assistant role.

According to the questionnaire ratings, teachers identified most learning benefits for case pupils in the secondary school, then in the special school and least in the primary school. This was corroborated by the thematic analysis which showed perceived gains in maths understanding and engagement in learning for the secondary teams. Gains were also seen to result for others in the class. In the special school the approach of giving an alternative to copying from the board was seen to result in positive learning gains. This approach was also seen to benefit others in the class and in other subjects. Despite the relatively low pupil gain 
ratings by the primary school team, analysis showed a recognition that pupil regrouping in the research lesson was enjoyed, leading to greater pupil confidence and use of learning resources.

The perceived benefits of the LS process for the EPs varied across the three teams. The special school EP was concerned about being cast in an expert role, while she wanted to act more collaboratively with teachers. Being in the LS team also took her away from her direct use of dynamic assessment (Elliott, 2003) in class to support teachers. But, she could see a role in:

'coaching them to think in those different ways and take... its dynamic assessment in collaboration with the teacher'.

She considered that the LS use of videoing could be used for:

'reviewing the learning of a child who was stuck with a teacher'.

The primary school EP who enjoyed the process saw the LS impact as positive. For him the use of videos to review the effects of teaching on children was the 'powerful bit' and 'a really nice concept' that he could use again. For the secondary school EP, the LS process enabled her to see 'consultation having a real difference in the classroom for that child'. She saw the LS team approach as 'invaluable'.

\section{Processes underlying outcomes}

The process or mechanism part of the CMO questionnaire covered the following LS processes: observing pupil learning constructively, analysing lessons to identify changes needed, working memory knowledge used constructively, engaging team members' interest, enabling supportive and constructive relationships. Table 3 shows that mean total process scores for each team were positive and high. This is consistent with much of thematic analysis results reported above. The highest rated process statements across all schools was about 
constructive / supportive team relationships, while the lowest, though still a positive rating, was about using working memory knowledge constructively.

Table 3 here

\section{Contexts affecting LS outcomes}

The context part of the CMO questionnaire covered the following contextual factors: timetable flexibilities made meetings possible, dedicated time to problem solve, school experience of teacher-centred CPD and experience of collaborative projects, teachers supported by school leaders and participants interested and well prepared/supported. Table 4 shows that mean total context scores for the primary and secondary school were positive but low compared to the higher special school scores. The most positive context factors across the schools was the commitment and preparation of support of participants. But, only the primary and secondary schools had negative or low contextual factors, not the special school. It is consistent with this pattern of rating, that only teachers in the primary and secondary schools talked about the need for contextual changes to make LS fit the culture of schools.

Table 4 here

\section{Discussion and conclusions}

This trial, which builds on and extends the findings of the previous trial (Norwich et al., 2016), in understanding how working memory ideas and practice can be used in an inter-professional LS that involved an EP in three types of UK schools to improve the teaching of pupils with various types of learning difficulties. Analysis showed how working memory knowledge informed the LS review and planning processes in different ways in each team. This depended on the previous familiarity of the EP with working memory perspectives, but also the novelty of 
LS practices in two of the three schools. Though there was evidence in each team of working memory concepts informing the review and planning process, there was a tendency across the teams to see the constructive LS dialogue as a more important process than using any working memory knowledge. The EPs also described how they used other psychological concepts and approaches in their LS contributions. In one case, a teacher who was actively critical of working memory ideas, came to accept its value. Though not included in this paper, the one day preparation conference evaluation did indicate that there might have been more emphasis on working memory ideas and practices at that stage. Nevertheless, as there has been no previous involvement of practitioner psychologists in a LS process before this study shows what can be done.

The analysis of the interactions within the LS teams showed that the use of working memory perspectives depended on how the EP interacted with the teachers. Two of the EPs were concerned about being cast as an expert, preferring to collaborate and use their consultancy skills. There were instances of the EPs asking questions in the interactions about what was going on and why rather than issuing explanations, though this was sometimes also done.. The more fine-grain analysis of team interactions also showed the extent of the productive nature of interactions that enabled new ideas and practices to be generated and tried. The importance of trust and the sense of collective responsibility for the process were evident in the analysis of the team interactions. The questionnaire analysis of the underlying LS processes converged with the above conclusions.

The teachers in the LS teams were clear about their EP's contribution to the LS process. In the special school, one teacher saw the EP as reaffirming what they already knew, but others in that team disagreed, giving specific evidence of the EP contribution. In the secondary school team the EP was seen to not only think in depth about the issues but also identified barriers 
and ways to deal with them. The primary school EP was seen to combine theoretical perspectives with practical approaches, as well as observational insights about pupils.

The trial also showed how the LS approach can be used with EPs involved in both direct and distance communication, which takes account of EPs being based outside schools. All teams reported an acceptable level of implementing the basic elements of the LS approach. However, there was some teacher absence in the primary LS team that affected the process, while the secondary EP, who chaired the meetings, described the challenge in keeping discussion to the pre-agreed 45 minutes. There was also some indication that case pupils were not always interviewed at the end of research lessons. Despite a fairly high level of implementation fidelity, when the teams considered the broader context of LS in their schools, it was clear that only in the special school was the wider context seen to be more supportive of LS processes. In the primary and secondary schools, timetable inflexibilities to release teachers to undertake the LS and a school inexperienced in teacher-centred CPD were factors seen to inhibit the LS process. This school difference might be related to greater organisational flexibilities in a special school compared to greater staffing and attainment pressures in the mainstream schools.

The outcomes of the LS process were assessed as lower in the primary than the other two schools. This may relate to implementation issues experienced in the primary school. It also fits with the team not being positive about the future use of LS in this school. Only in the secondary school were case pupil outcomes judged at the same positive level as teacher outcomes of LS. In both the primary and special school the teacher outcomes were judged as more positive than case pupil outcomes (see Figure 4). This may relate to the secondary school using the LS to try a more novel teaching approach than the other two schools. However, evidence of pupil gains from the LS process were by teacher interview and 
questionnaire. Monitoring changes of case pupils' maths performance needs to be used in future research.

Despite the overall positive evaluation of this inter-professional LS trial, there were some critical perspectives about LS. The primary school EP questioned the principle of the LS focus on case pupils rather than focusing on the teaching. This arose from his experience of video interaction guidance (VIG) analysis (Kennedy, Landor \& Todd. 2010), a technique used by EPs that focuses more on adults in parent-child interaction. This is a challenging point about the current design of Lesson Studies, which has an explicit learning/learner focus but also does take account of teaching. But it is a point which misses the reason for LS's explicit learning focus which is to counter the dominance of teaching evaluation in school accountability processes.

Other issues arose about when LS might be useful in the current context of English schooling. Despite being very positive about LS, the secondary EP saw LS as best suited to occasional use when there is a 'really sticky' problem. A primary senior teacher also saw LS as useful for 'particularly challenging cohorts of children'. Covering teachers to participate in LS was for this teacher the key issue, which connects with the view of several participants that LS occurred in a context that had little place for teacher collaboration. Members of the primary and secondary teams also talked about the need for a 'culture change' in schools.

This study extends understanding of how with the presence of an inter-professional team, research lessons are sites for teacher enquiry where research informed knowledge is brought into contact with teachers' subject content and pedagogic knowledge in the planning and enacting of specific lessons. This approach reaffirms the central role of teacher research in the relationships between theoretical knowledge and teaching practice (Norwich et al. 2016). Seen in the context of other collaborative problem solving approaches 
used by EPs internationally, this study also shows what is distinctive about an interprofessional LS approach for EPs.

EPs joining a team of teachers in developing their teaching of case pupils, informed by relevant professional and research informed knowledge, can deploy their psychological knowledge and their consultancy and problem solving skills within a set of inter-professional reflective practice principles and procedures.

Acknowledgements:

The authors wish to thank the participants in the school and psychological services who participated in the study, and the CSSIS University of Exeter for funding.

\section{References}

Alloway, T (2007). Automated Working Memory Assessment manual. London: Pearson Publishers.

Apter, B.J.P. (2012) Do computerised training programmes designed to improve working memory work? Educational Psychology in Practice, 28:3, 257-272.

Bennett, S. \& Monsen, S.J. (2011). A critical appraisal of four approaches which support teachers' problem-solving within educational settings. Educational Psychology in Practice 27(1):19-35.

Chia, N.K.H. (2013). Modified lesson study within the integrated teaching-learning framework for professional development of special education teachers. Educational Research International, 2, 1, 22-33.

Creese, A., Daniels, H. \& Norwich, B. (1997). Teacher support teams in primary and secondary schools. London: David Fulton Publishers.

Dudley, P. (2012). Lesson Study development in England: from school networks to national policy, International Journal for Lesson and Learning Studies, 1, 1, 85-100. 
Elliott, J. (2003). Dynamic Assessment in Educational Settings: Realising Potential.

Educational Review 55(1): 15-32.

Gathercole, S.E. (2008). Working memory in the classroom. The Psychologist, 21(5), 382-385.

Gathercole, S.E. \& Alloway, T.P. (2008). Working memory and learning: A practical guide for teachers. London: Sage.

Goei, S.L., Cai, N., \& Kee, N. (2017). Lesson Study in Inclusive Educational Settings. (eds., in press) Taylor \& Francis.

IJLLS (2018) International Journal of Lesson and Learning Studies past issues. Accessed on 5.1.18 at http://www.emeraldinsight.com/journal/ijlls

Kennedy, H., Landor, M. \& Todd. L. (2010) Video Interaction Guidance as a method to promote secure attachment. Educational and Child Psychology Vol. 27 No. 3.

Lewis, C. (1998). A lesson is like a swiftly flowing river: how research lessons improve Japanese education, American Educator, 10, 9, 12-17, 50-51.

Lewis, C. \& Hurd, J. (2011). Lesson Study; step by step. Portsmouth, NH: Heinemann. Lewis, C., Perry, R., Hurd, J. \& O'Connell, M. P. (2006). Lesson study comes of age in North America. Phi Delta Kappan, 88(04), 273-281.

Norwich, B., Dudley, P. \& Ylonen, A. (2014). Using lesson study to assess pupils' learning difficulties. International Journal for Lesson and Learning Studies 3, 2, 192-207.

Norwich, B and Jones J. (2014). Lesson Study: making a difference to teaching pupils with learning difficulties. London: Continuum Publishers.

Norwich, B., Koutsouris, G., Fujita, T., Ralph, T., Adlam, A. \& Milton, F. (2016)

Exploring knowledge bridging and translation in lesson study using an inter-professional team. International Journal for Lesson and Learning Studies, 5, 3, 180-195.

Norwich, B., \& Ylonen, A. (2013) Design based research to develop the teaching of pupils with moderate learning difficulties (MLD): Evaluating lesson study in terms of pupil, teacher and school outcomes, Teaching and Teacher Education, 34, 162-173. 
NVIVO (2018) Software for qualitative data analysis. Accessed on 5.1.18 at http://www.qsrinternational.com/nvivo/nvivo-products

Parks, A.N. (2008). Messy learning: Preservice teachers' lesson-study conversations about mathematics and students. Teaching and Teacher Education, 24, 1200-1216

Robson, C. and McCarten,K. (2015) Real World Research ( $4^{\text {th }}$ ed.). London: Wiley.

Takahashi, A. and Yoshida, M. (2004), Ideas for establishing lesson-study communities, Teaching Children Mathematics, 10, 9, 436-443.

Ylonen, A. and Norwich, B. (2013). Professional learning of teachers through a lesson study process in England Contexts: mechanisms and outcomes. International Journal for Lesson and Learning Studies, 2, 2,137-154.

\section{APPENDIX:}

Themes used in qualitative analysis:

\section{TEAM INTERACTIONS}

Collaboration

Coordination and questioning each other Issues

\section{KNOWLEDGE USE AND EXCHANGE}

Working memory and other psychological areas

\section{PERCEIVED CONTRIBUTION OF EPS}

\section{LS OUTCOMES}

For case pupils

For teachers

What is valuable about LS

For EP 
